\title{
An anthropometric study of young Indian men for bottom wear sizing
}

\section{Manoj Tiwari*}

Department of Fashion Technology,

National Institute of Fashion Technology,

Jodhpur-342037, India

Email: manoj.tiwari@nift.ac.in

*Corresponding author

\section{Noopur Anand}

Department of Fashion Technology,

National Institute of Fashion Technology,

New Delhi - 110016, India

Email: noopur.anand@nift.ac.in

\begin{abstract}
The objective of the paper is to develop a standardised bottom-wear body size chart for young Indian men through a pan-India anthropometric survey. The research involved a pan-India anthropometric survey of 14 crucial body dimensions (required for bottom-wear) of 2,401 Indian male aged between 18-29 years. Statistical analysis of the anthropometric data was done through multivariate analysis using principal component analysis (PCA) and two-step cluster analysis as data mining techniques using SPSS 16. The developed size charts were validated statistically by calculating aggregate loss based on Euclidean distance. The research resulted in the selection of six body size charts based on standard deviation as well as cluster analysis. The aggregate loss values observed between $1.81 \mathrm{~cm}$ to $2.42 \mathrm{~cm}$. The percentage coverage of the population ranged between $76.22 \%$ to $97.21 \%$ with a number of size categories ranged from 32 to 40 . The research fills the gap in the Indian bottom-wear manufacturing setup by providing size chart developed as per anthropometric make of young Indian male. The developed size chart is envisaged to provide well-fitting bottom-wear to Indian costumers thereby reducing loss of sales and increasing consumer satisfaction.
\end{abstract}

Keywords: anthropometry; young Indian male; bottom-wear; size charts; statistical analysis; Euclidean distance.

Reference to this paper should be made as follows: Tiwari, M. and Anand, N. (2020) 'An anthropometric study of young Indian men for bottom wear sizing', Int. J. Forensic Engineering and Management, Vol. 1, No. 1, pp.24-41.

Biographical notes: Manoj Tiwari is working as an Associate Professor with Department of Fashion Technology at NIFT since 2009. He has worked on 'Size chart standardization of bottom-wear for Indian male youth (18-29 years)' in his Doctoral research. He has more than 13 years of industry and academic experience with reputed organizations in India and abroad. $\mathrm{He}$ has published and presented $40+$ research papers and articles in the national and international level conferences and journals along with book titled Industrial Engineering in Apparel Manufacturing, co-authored with Professor Prabir Jana, 
NIFT Delhi. His key areas of interest include industrial engineering, ergonomics, and apparel technology management. He is a core team member of India size project for undertaking national sizing survey of India.

Noopur Anand is an academician with more than 22 years of experience. Her specialisation is in field of textiles and clothing. Her research interests are in areas of garment fit and sizing, pattern engineering and product development with special focus on 'Smart Garments'. She has authored a book on Smart Maternity-wear which documents specifications for maternity wear having serviceable life beyond pregnancy, i.e., it fits well pre, during and post pregnancy period. She has also filed for patent for self-defence wearable - an anti-molestation jacket for protection of women from assailers. She is currently a Professor in Department of Fashion Technology at NIFT and is Principle Investigator of India size project for undertaking national sizing survey of India.

This paper is a revised and expanded version of a paper entitled 'Development of bottom-wear size chart for Indian male youth' presented at International Conference, Humanizing Work and Work Environment 2017, AMU, Aligarh, 8-10 December 2017.

\section{Introduction}

Humans aspire to achieve satisfaction from there surrounding environment by having functional, safe, user-friendly and aesthetic personal space as well as workspace. Same holds good for the clothing wherein a good fit becomes an important criterion for evaluation of performance of the garment and consumer satisfaction. The approach should be to consider human variability while designing (Bridger, 2003). Wearing clothes of right size according to body measurements in imperative to get comfort and fit (Gupta and Zakaria, 2014b). Sizing is one of the basic requirements for industrial clothing production, where garments are manufactured considering the body dimensions of the consumers (Bridger, 2003). Sizing systems have been developed based on the body measurements taken across the representative section of the population (Kunick, 1984). Various countries, including the USA and the UK, have developed their sizing systems using traditional anthropometric techniques of data collection, i.e., manual as well as modern technology (NTC, 2003). India with the largest young population is one of the biggest consumer markets with the presence of national and international apparel brands. Unfortunately, India doesn't have its anthropometric database hence the Indian apparel sector is bound to use size charts of western countries (Chakrabarty, 1997; Anand, 2011). There has been a little-reported research work done in India as far as anthropometric applications in apparel sizing are concerned (Gupta, 2010). And ones which have been undertaken are either not for the purpose of clothing or did not have statistically justified sample size to represent the entire nation. However, few brands have come up with their measurement charts but they are able to cater to small number of people buying there own brand and are not able to create a size chart for Indian population. Moreover, such brand specific size charts have created more confusions in mind of the costumer as they vary between brands and at times within brand as well. As a result, the young consumers have to compromise with the fit of the garments. This establishes the research gap- to 
achieve well fitted bottom wear there is need to create a standardised body size chart which will be representative of Indian population through a pan-India anthropometric survey of the target population. This paper aims to develop standardised bottom-wear body size chart for Indian male young consumers through a pan-India anthropometric survey.

Indian National Youth Policy 2014 defines youth as those aged 15 to 29 (Ministry of Youth and Sports, 2014). The human body goes through a physiological and pathological process affecting human growth regarding shape and size. It is an established fact that, a child evolves as a youth, adult and eventually attains old age with significantly visible changes in shape and size of the body. Many of the researchers including Pheasant and Haslegrave in their book Body Space - Anthropometry, Ergonomics and the Design of Work state that the age at which one reaches the 'anthropometric adulthood' is by no means clear-cut. However, the growth standards conventionally stop at the age of 16 years for girls and the age of 18 years for boys (Pheasant and Haslegrave, 2006). This is the reason of the suitability of starting age that is 18 years for the anthropometric survey of young Indian male in this research. Hence the age bracket from 18-29 years was chosen for the research study.

This research paper discusses, a nationwide anthropometric survey conducted spanning six geographic regions to develop bottom-wear size charts for young Indian male. The sample size covered 2,401 valid subjects of Indian young male aged between 18-29 years. In total 14 body measurements, necessary for bottom-wear were recorded through manual body measurement process following ISO 8559 (1989) standard. Subsequently, body size charts were developed through statistical data analysis using various tools and techniques. The sizing analysis involved data mining applying multivariate analysis using principal component analysis (PCA) and two-step cluster analysis. The size charts developed, were validated statistically by calculating aggregate loss based on Euclidean distance.

\section{Review of literature}

The first step in achieving a well fitted garment is to have accurate body dimensions, which unfortunately India does not have and Indian consumers have to use size charts of other countries (such as the USA or the UK anthropometric dimensions). There is non-availability of comprehensive anthropometric data for Indian male which can represent the whole country and the dimensions can be used for various applications including apparel, as the previous research was done on only 500 subjects which may not be treated as statistically justified sample size for entire nation hence might not represent the target population in the true sense. At present, the Indian garment industry has to use size charts of other countries (such as the USA or the UK anthropometric dimensions) for product developments. That does not fit us well, as the Indian anthropometric dimensions differ from these countries (Anand, 2011). The reason of not having Indian size chart for apparel may be that the demand for such size charts was not felt in the past due to the type of garments traditionally used in India, particularly the drape wear like saries for female and dhoties, lungis for males (Gupta, 2008). The other reasons may be need of very little stitching in such garments which can be done by local tailors or even at home, and lastly level of fashion and consciousness to fit in Indian culture. 
In recent times where India is passing through a major retail revolution resulting in changing habits of the Indian young consumers, western clothes have taken the lead. So, the need was never felt till last few years, but due to the shift of preference from traditional clothing to the western clothing, a demand of improved fit in the garment has increased and so there is a need for size chart based on Indian anthropometric dimensions.

The young population of India is a demographic dividend to the Indian economy. Even after such a significant young consumer base for bottom-wear product categories, it is unfortunate that the Indian consumers have to face fit issues in clothing, due to non-availability of standardised Indian size charts. This presents a conducive environment and base for carrying out this research work and developing a comprehensive anthropometric data of young Indian male which can represent the whole country and the dimensions can be used for various applications.

\section{Research methodology}

\subsection{Subject}

A nation-wide anthropomorphic survey of young Indian male (18-29 years) was conducted, where body measurements of the subjects were recorded from six geographical zones (as Eastern India, Western India, Northern India, Southern India, Central India, and North-East India) covering all the states of India. A statistically justified sample size @ 95\% confidence level and 5\% error level (Bartlett et al., 2001; Levin and Rubin, 2004) were covered by each zone making total sample size 2,304 subjects from all six geographic zones. Total valid subjects measured while anthropometric survey was 2,401 subjects. The subject categories involved primarily students and employed people from different organisations.

\subsection{Sample size determination}

To determine the sample size for the proposed research, the level of confidence and the level of acceptable error were considered as $95 \%$ and $5 \%$ respectively. The formula as suggested by Cochran (1977) is used when the population size is infinite (cited in Shodhganga-Inflibnet, 2013).

$$
\text { Sample size }(n)=\frac{[(z * z) *(p)(1-p)]}{d * d}
$$

where

$z \quad$ is the value for the selected confidence level (it is 1.96 for the confidence level of $95 \%$ for the proposed survey)

$p \quad$ is the probability of occurrence of the activity (it is 0.50 as $p$ and $(1-p)$ is 0.50 for the proposed survey)

$d$ is the level of error or the acceptable error percentage (it is 0.05 or $5 \%$ for the proposed survey). 
Subjects for the anthropometric survey in this research were chosen following cluster sampling, where entire nation was divided into six geographic regions or clusters. A statistically justified sample size that is 384 subjects @ 95\% confidence level and 5\% error level (Levin and Rubin, 2004; Bartlett et al., 2001) were covered by each zone making total subjects 2,304 aged between 18 and 29 years were selected randomly. In total 2,401 subjects (97 subjects more than the required sample size) across the nation from six geographic zones participated in the anthropometric survey, which is statistically justified to represent the young Indian male population of the nation.

For survey in this research cluster sampling technique based on geographical regions was preferred over stratified sampling technique based on the age groups. The reason for the same is that review of literature established that the body growth patterns in young adult male do not change with age post 18-19 years which is the stage when they attain physical growth maturity (this was later re-established through primary data collected), hence sampling basis geographical regions were favoured over age group.

\subsection{Body dimensions}

In total 14 body dimensions essentially required for bottom-wear were selected for measurements. Inside leg length, outside leg length, waist girth, seat girth (hip girth), thigh girth, knee girth, ankle girth, and body rise are required for developing a full-length trouser (Cooklin, 1992; Aldrich, 2006). According to Armstrong (2006), measurements from waist to ankle, crotch depth, front and back hip arc, front and back waist arc and ankle girth are required to develop a trouser.

\subsection{Procedure and equipment}

The definitions and landmarks of body dimensions followed were as per the ISO 8559:1989 standard and ISO 7250-I (2008) standard (ISO 8559, 1989; ISO 7250(I), 2008). The body survey was conducted manually using anthropometer (sliding stadiometer of length 210 centimetre and least count $1.0 \mathrm{~mm}$ ) and a certified flexible non-stretchable steel tape (length 200 centimetre and least count $1.0 \mathrm{~mm}$ ) used for anthropometric studies. While taking, measurements subjects were kept bareheaded and without shoes. Skinny comfort fit knitted shorts were used while taking body measurements making sure that it was neither adding to the body dimension or compressing the body resulting in loss of measurement (Beazley, 1997; ISO 7250(I), 2008). A mirror behind the subject was fitted on the wall to ensure the correct landmark positioning and placement of measuring tape.

The body measurements were taken manually by the expert having experience of anthropometry. In order to minimise human errors and instrument errors, body measurement of all the subjects were taken by same measurer using same set of equipment. The entire anthropometric survey was conducted under guidance of an observer having more than 20 years of experience in anthropometry and anthropology. 


\section{Results and discussion}

\subsection{Data Preparation and Initial analysis}

The data was cleaned by filtering out outlier values which were abnormal and falling beyond \pm three $\sigma$ (standard deviation) limits (Hsu, 2009a; Moon and Nam, 2003). The initial analysis of the anthropometric data involved frequency distribution for age, profile and geographic distribution of the subjects, univariate analysis with basic statistics using mean, median, mode, and range of minimum and maximum values of the anthropometric variables. Subject profile regarding age, profession and geographical region-wise distribution are mentioned in Tables 1 to 3 .

Table 1 Age wise distribution of the subjects

\begin{tabular}{lcccc}
\hline Age (yrs.) & Frequency & Percent & Valid percent & Cumulative percent \\
\hline 18 & 318 & 13.2 & 13.2 & 13.2 \\
19 & 336 & 14.0 & 14.0 & 27.2 \\
20 & 346 & 14.4 & 14.4 & 41.6 \\
21 & 312 & 13.0 & 13.0 & 54.6 \\
22 & 243 & 10.1 & 10.1 & 64.8 \\
23 & 170 & 7.1 & 7.1 & 71.8 \\
24 & 140 & 5.8 & 5.8 & 77.7 \\
25 & 132 & 5.5 & 5.5 & 83.2 \\
26 & 137 & 5.7 & 5.7 & 88.9 \\
27 & 81 & 3.4 & 3.4 & 92.3 \\
28 & 83 & 3.5 & 3.5 & 95.7 \\
29 & 103 & 4.3 & 4.3 & 100.0 \\
\hline Total & 2401 & 100.0 & 100.0 & \\
\hline
\end{tabular}

Table 2 Profession wise distribution of the subjects

\begin{tabular}{lcccc}
\hline Profession & Frequency & Percent & Valid percent & Cumulative percent \\
\hline Employed & 544 & 22.7 & 22.7 & 22.7 \\
Others & 4 & 0.2 & 0.2 & 22.8 \\
Self-employed & 26 & 1.1 & 1.1 & 23.9 \\
Student & 1827 & 76.1 & 76.1 & 100.0 \\
Total & 2401 & 100.0 & 100.0 & \\
\hline
\end{tabular}

Table 3 Geographic region wise distribution of subjects

\begin{tabular}{lcccc}
\hline Geographical region & Frequency & Percent & Valid percent & Cumulative percent \\
\hline Central India & 370 & 15.4 & 15.4 & 15.4 \\
Eastern India & 351 & 14.6 & 14.6 & 30.0 \\
North-East India & 379 & 15.8 & 15.8 & 45.8 \\
Northern India & 414 & 17.2 & 17.2 & 63.1 \\
Southern India & 360 & 15.0 & 15.0 & 78.1 \\
Western India & 527 & 21.9 & 21.9 & 100.0 \\
\hline Total & 2401 & 100.0 & 100.0 & \\
\hline
\end{tabular}


Age-wise frequency distribution of the subjects of the anthropometric survey is mentioned in Table 1. It was observed that around $83 \%$ of the subjects were below age of 25 years and remaining subjects were above 25 years to 29 years.

\subsection{Body dimension statistics}

Univariate analysis of anthropometric data for all the 14 body dimensions was conducted using basic statistical tools. Table 4 displays body dimension statistics with anthropometric measurements (in centimetre) of all the subjects covered under the size survey.

Some basic statistical measures including mean, median, mode, standard deviation and range with minimum and maximum values were calculated for each of the body dimension measured. It was observed that the vertical dimensions (height, crotch height and waist height) have almost similar ranges between 38 centimetres to 41 centimetres. While the horizontal waist girth related dimensions (true waist girth, waist girth below 1" of true waist, waist girth below 2" of true waist, high hip girth and hip girth) witnessed a comparatively wider range between 48 centimetres to 57 centimetres. Thigh girth, knee girth and ankle girth dimensions witnessed a narrow range which can also be reflected from the standard deviation values of respective dimensions.

Table 4 Body dimension statistics

\begin{tabular}{lccccccc}
\hline $\begin{array}{l}\text { Body dimension } \\
\text { (centimetres) }\end{array}$ & Mean & Median & Mode & $\begin{array}{c}\text { Standard } \\
\text { deviation }\end{array}$ & Range & $\begin{array}{c}\text { Min. } \\
\text { value }\end{array}$ & $\begin{array}{l}\text { Max. } \\
\text { value }\end{array}$ \\
\hline Height & 171.33 & 171.00 & 170.00 & 6.16 & 40.00 & 150.50 & 190.50 \\
True waist girth & 73.26 & 72.00 & 70.00 & 7.91 & 50.00 & 54.00 & 104.00 \\
Girth below 1" of T/waist & 75.16 & 75.00 & 75.00 & 8.16 & 54.00 & 55.00 & 109.00 \\
Girth below 2", of T/waist & 77.37 & 77.00 & 78.00 & 8.02 & 57.00 & 56.00 & 113.00 \\
High hip girth 4" below & 80.47 & 80.00 & 80.00 & 7.63 & 54.00 & 61.00 & 115.00 \\
from T/Waist & & & & & & & \\
Hip girth & 88.34 & 88.00 & 89.00 & 7.24 & 48.00 & 67.00 & 115.00 \\
Thigh girth & 48.36 & 48.00 & 48.00 & 4.45 & 32.00 & 32.00 & 64.00 \\
Knee girth & 34.92 & 35.00 & 34.00 & 2.40 & 19.00 & 28.00 & 47.00 \\
Crotch height & 74.08 & 75.00 & 75.00 & 5.14 & 41.00 & 55.00 & 96.00 \\
Waist height & 107.45 & 108.00 & 107.00 & 5.77 & 38.10 & 88.90 & 127.00 \\
Front rise & 36.25 & 36.00 & 36.00 & 2.21 & 21.00 & 25.00 & 46.00 \\
Back rise & 38.72 & 39.00 & 39.00 & 2.24 & 19.26 & 29.00 & 48.26 \\
Total crotch length front & 74.97 & 75.00 & 75.00 & 4.17 & 39.00 & 55.00 & 94.00 \\
to back as U & & & & & & & \\
Ankle girth & 31.71 & 32.00 & 32.00 & 1.50 & 10.33 & 26.67 & 37.00 \\
\hline
\end{tabular}

The body measurement data were analysed for the normal distribution. It was observed that the anthropometric data (body measurement data) was nearly normally distributed. Sample adequacy and sphericity of the body measurement data was tested using Kaiser Meyer Olkin (KMO) measure of sampling adequacy and Bartlett's test of sphericity. KMO value observed was 0.810 which was very good in comparison to standard acceptable KMO Value 0.60. Bartlett's test of sphericity also observed suitable. Internal 
consistency and uni-dimensionality of the data was tested using Cronbach's alpha measure. The Cronbach's alpha value observed was 0.910 which was good compared to the standard acceptable Cronbach's alpha value 0.60 .

\subsection{Sizing analysis}

The sizing analysis involved data mining applying multivariate analysis using principal component analysis (PCA) and two-step cluster analysis.

\subsubsection{Principal component analysis}

The principal component analysis (PCA) with varimax rotation was applied to identify the key or most important factors useful for developing the body size charts. In order to gain the parsimony, the number of factors extracted should be less. To achieve this objective, following the standard practice, the factors indicating eigenvalues more than 1.0 were selected. Figure 1 illustrates the scree plot of the graphical representation of eigenvalues of the factors extracted from PCA.

Figure 1 Scree plot

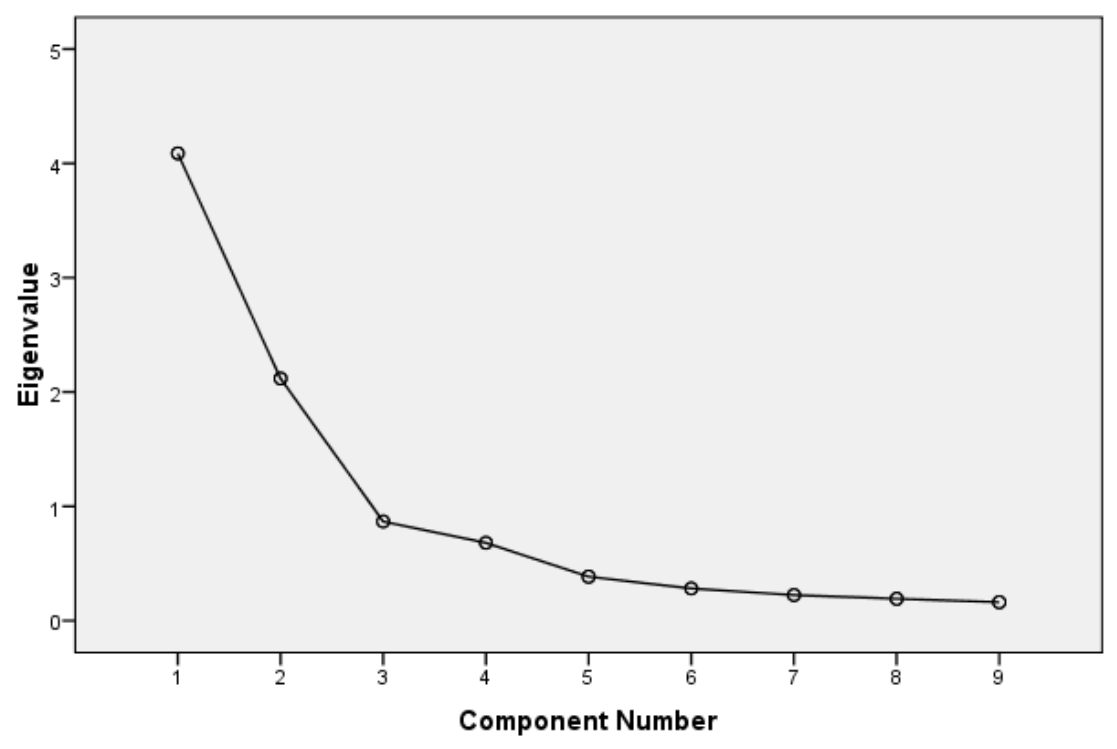

Variance explained in the principal component analysis is mentioned in Table 5. It was observed that two components were having Eigenvalue more than 1.0 and together explained $69 \%$ of the total variance (as shown in Table 5). These two components extracted were horizontal (girth) and vertical (height) dimension. This result of variance explained by the first two components was found at par with the findings of other research works conducted. Zakaria (2011) while developing sizing system for functional clothing-uniform for school children observed cumulative variance $83.5 \%$ and $69 \%$ covered by the first two components for children age group 7-12 years and 13-17 years respectively. Hrženjak and Ujevic (2015) extracted four components while developing 
sizing system for girls (aged between 13-20 years) and observed variance covered by these components was $68.1 \%$.

Table 5 Principal component analysis

\begin{tabular}{|c|c|c|c|c|c|c|c|c|c|}
\hline \multicolumn{10}{|c|}{ Total variance explained } \\
\hline \multirow[b]{2}{*}{ 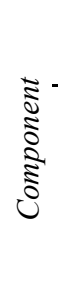 } & \multicolumn{3}{|c|}{ Initial eigenvalues } & \multicolumn{3}{|c|}{$\begin{array}{l}\text { Extraction sums of } \\
\text { squared loadings }\end{array}$} & \multicolumn{3}{|c|}{$\begin{array}{l}\text { Rotation sums of squared } \\
\text { loadings }\end{array}$} \\
\hline & $\overbrace{}^{\sqrt[5]{3}}$ & 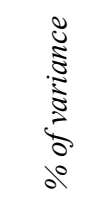 & 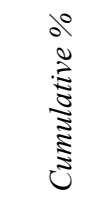 & $\overbrace{}^{\sqrt[5]{0}}$ & 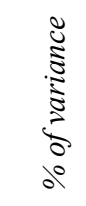 & 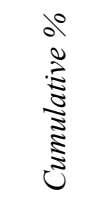 & $\underbrace{\pi}$ & $\begin{array}{c}\tilde{J} \\
\vdots \\
\vdots \\
\vdots \\
\vdots \\
0 \\
0 \\
0\end{array}$ & 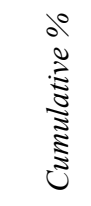 \\
\hline 1 & 4.10 & 45.55 & 45.55 & 4.10 & 45.55 & 45.55 & 3.56 & 39.64 & 39.64 \\
\hline 2 & 2.11 & 23.51 & 69.07 & 2.11 & 23.51 & 69.07 & 2.64 & 29.43 & 69.07 \\
\hline 3 & .863 & 9.58 & 78.65 & & & & & & \\
\hline 4 & .681 & 7.56 & 86.22 & & & & & & \\
\hline 5 & .381 & 4.23 & 90.45 & & & & & & \\
\hline 6 & .282 & 3.13 & 93.59 & & & & & & \\
\hline 7 & .222 & 2.47 & 96.06 & & & & & & \\
\hline 8 & .192 & 2.13 & 98.19 & & & & & & \\
\hline 9 & .162 & 1.80 & 100.00 & & & & & & \\
\hline
\end{tabular}

Note: Extraction method - principal component analysis.

\subsubsection{Selection of key dimensions}

Rotated component matrix with Varimax rotation for the body dimensions of the subjects measured during sizing survey is shown in Table 6 . The body dimensions with factor loading $\geq 0.75$ are highlighted with bold letters. Examination of the factor loading confirmed that the variables under a factor or component are highly correlated with each other. The girth related (horizontal) dimensions are falling in one category having a strong positive correlation with the first component. While the other set of dimensions is length related (vertical) dimensions. As a result of this factor loading analysis with varimax rotation (as shown in Table 6), two components extracted were horizontal (girth) and vertical (length) dimensions. This eventually resulted in selection of key dimensions for the sizing system. Thigh girth and true waist girth showed the highest factor loading as 0.882 and 0.875 respectively with the girth component, while waist height and crotch height witnessed the highest factor loading as 0.926 and 0.906 respectively with the length component.

It was noted that thigh girth has witnessed maximum factor loading in the girth component, though in practice thigh girth is not used as key dimension in development of sizing systems. Waist girth showed marginally less correlation than thigh girth. Since key dimensions should be a measurement familiar to the consumer and easy to measure waist girth was selected over thigh girth as a key dimension. 
Table 6 Rotated component matrix - PCA

\begin{tabular}{lcc}
\hline \multicolumn{3}{c}{ Rotated component matrix } \\
\cline { 2 - 3 } & \multicolumn{2}{c}{ Component } \\
\cline { 2 - 3 } & 1 & 2 \\
Height & (Horizontal/girth) & (Vertical/height) \\
True waist girth & 0.199 & $\mathbf{0 . 8 9 0}$ \\
Hip girth & $\mathbf{0 . 8 7 5}$ & 0.043 \\
Thigh girth & $\mathbf{0 . 8 5 5}$ & 0.183 \\
Knee girth & $\mathbf{0 . 8 8 2}$ & 0.031 \\
Crotch height & $\mathbf{0 . 8 0 6}$ & 0.057 \\
Waist height & 0.049 & $\mathbf{0 . 9 0 6}$ \\
Total crotch length front to back as U & 0.124 & $\mathbf{0 . 9 2 6}$ \\
Ankle girth & 0.388 & 0.282 \\
\hline
\end{tabular}

Note: aRotation converged in 3 iterations.

For key dimensions for length, waist height, crotch height and height showed a very strong correlation to the length factor. In common practice, all of these three have been chosen to be used as a key dimension in different sizing systems. In India, crotch height is popularly used as one of the key dimensions. ISO 3636 (1977) indicates waist girth and inside leg length as control dimensions for men's lower body garments. In BSI sizing system uses waist height (outside leg length) as key dimension (Chun-Yoon and Jasper, 1993). Similarly, Hsu (2009) used outside leg length as one of the key dimension in sizing system development for Taiwanese female (Hsu, 2009a). The Korean sizing systems use height as one of the key dimensions and size categories have been defined by height (Ashdown, 1998; Chun, 2014). Chung et al. (2007) developed a sizing system for Taiwanese school students and used height as one of the key dimension. Zakaria (2014) used height as one of the key dimension while developing size chart for school children in Malaysia. Finally, an attempt was made to develop three separate sizing systems considering each of three vertical dimensions height, waist height and crotch height as a key dimension in a sizing system.

\subsubsection{Cluster analysis}

Cluster analysis was applied to classify the anthropometric data into significantly different clusters (classes) of control body dimensions for size chart development. Data classification was done through two-step Cluster analysis method ensuring elimination of subjectivity on the number of some clusters. Following the results from PCA, three combinations were worked out as Waist girth - Height, Waist girth - Waist Height and Waist girth - Crotch height. The cluster distribution with the percentage of subjects in the classes identified in each of the three combinations is shown in Table 7. It can be noticed that the waist girth - height, waist girth - waist height and waist girth - crotch height resulted in five, three and six classes of the subjects respectively. To check and confirm the significantly distinguished segmentation, analysis of variance (ANOVA) was applied to the clusters created for each of the combinations. 
Table 7 Cluster combinations

\begin{tabular}{lcccc}
\hline \multicolumn{4}{c}{ Cluster distribution } & \\
\hline & Classes & $N$ & $\%$ of combined & $\%$ of total \\
\hline Waist girth-height & 1 & 341 & $14.2 \%$ & $14.2 \%$ \\
& 2 & 671 & $27.9 \%$ & $27.9 \%$ \\
& 3 & 451 & $18.8 \%$ & $18.8 \%$ \\
Waist girth-waist height & 4 & 259 & $10.8 \%$ & $10.8 \%$ \\
& 5 & 679 & $28.3 \%$ & $28.3 \%$ \\
& 1 & 2,401 & $100.0 \%$ & $100.0 \%$ \\
& 2 & 701 & $29.2 \%$ & $29.2 \%$ \\
Waist girth-crotch height & 3 & 1,013 & $42.2 \%$ & $42.2 \%$ \\
& 1 & 687 & $28.6 \%$ & $28.6 \%$ \\
& 2 & 2,401 & $100.0 \%$ & $100.0 \%$ \\
& 3 & 394 & $16.4 \%$ & $16.4 \%$ \\
& 4 & 419 & $17.5 \%$ & $17.5 \%$ \\
& 4 & 700 & $29.2 \%$ & $29.2 \%$ \\
& 241 & $10.0 \%$ & $10.0 \%$ \\
& 5 & 434 & $18.1 \%$ & $18.1 \%$ \\
& 6 & 213 & $8.9 \%$ & $8.9 \%$ \\
& & 2,401 & $100.0 \%$ & $100.0 \%$ \\
\hline
\end{tabular}

\section{Development of size charts}

The development of the body size charts was done for three combinations of the control dimensions which are waist girth-height, waist girth-waist height and waist girth-crotch height. The body size charts were developed by the following two methods which are the cluster analysis and the standard deviation (see Figure 2). This resulted in total of six different body size charts.

Figure 2 Body size chart combinations

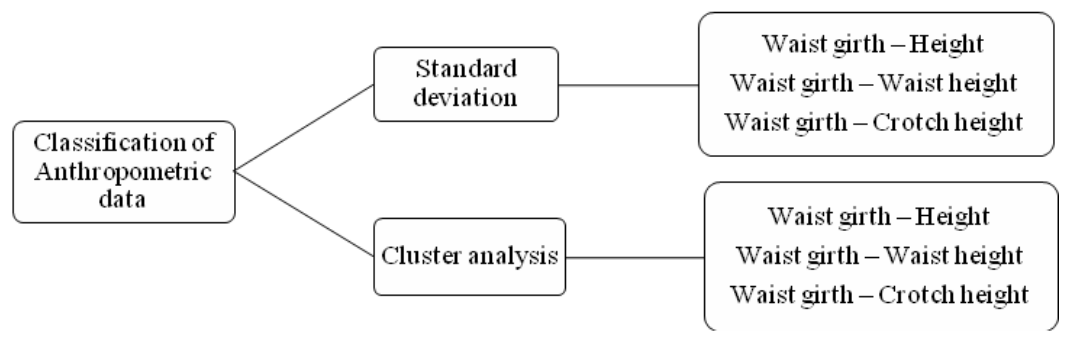

The development of the sizing system involved selecting size range, size interval, size scale and size roll. 
Table 8 Example of size chart for class 1 (waist girth-waist height)

\begin{tabular}{|c|c|c|c|c|c|c|c|c|c|c|}
\hline \multirow{2}{*}{$\frac{\text { Category }}{\text { Class } 1}$} & \multicolumn{10}{|c|}{ Bottom-wear (Male - 18-29 Years) } \\
\hline & \multicolumn{10}{|c|}{ Waist girth-waist height } \\
\hline \multirow{2}{*}{ 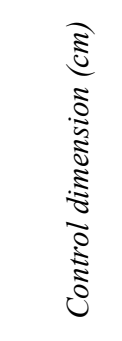 } & 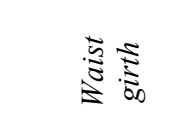 & in & & 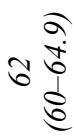 & & & aे & & $\frac{a}{d}$ & $\hat{2} \frac{a}{2}$ \\
\hline & 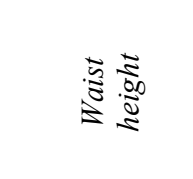 & 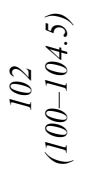 & ๙ิ $\frac{\hat{a}}{a}$ & $\begin{array}{l}\hat{a} \\
\hat{a} \\
\hat{a} \\
\hat{a}\end{array}$ & 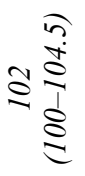 & $\hat{a} \frac{a}{a}$ & 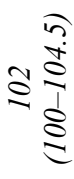 & $\begin{array}{l}\hat{a} \\
\hat{a} \\
\frac{1}{a}\end{array}$ & 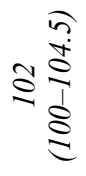 & $\begin{array}{l}\hat{a} \\
\hat{a} \\
\hat{a}\end{array}$ \\
\hline \multirow{12}{*}{ 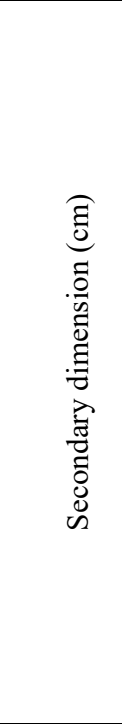 } & Height & 165 & 159 & 161 & 166 & 161 & 166 & 160 & 167 & 167 \\
\hline & $\begin{array}{l}\text { Girth below } \\
1 \text { inch of } \\
\text { T/waist }\end{array}$ & 60 & 63 & 64 & 65 & 68 & 68 & 74 & 73 & 79 \\
\hline & $\begin{array}{l}\text { Girth below } \\
2 \text { inch of } \\
\text { T/waist }\end{array}$ & 63 & 65 & 67 & 67 & 70 & 71 & 76 & 76 & 81 \\
\hline & High hip girth & 67 & 68 & 71 & 72 & 74 & 74 & 79 & 79 & 83 \\
\hline & Hip girth & 76 & 75 & 79 & 80 & 81 & 82 & 86 & 86 & 91 \\
\hline & Thigh girth & 41 & 45 & 43 & 43 & 46 & 46 & 46 & 48 & 49 \\
\hline & Knee girth & 31 & 34 & 33 & 33 & 34 & 34 & 34 & 34 & 35 \\
\hline & Crotch height & 70 & 60 & 66 & 70 & 66 & 70 & 67 & 71 & 69 \\
\hline & Front rise & 34 & 35 & 35 & 36 & 35 & 36 & 35 & 36 & 34 \\
\hline & Back rise & 36 & 37 & 37 & 38 & 37 & 38 & 38 & 38 & 38 \\
\hline & Crotch length & 71 & 72 & 72 & 73 & 72 & 73 & 74 & 74 & 72 \\
\hline & Ankle girth & 29 & 31 & 30 & 30 & 31 & 31 & 31 & 31 & 32 \\
\hline \multicolumn{2}{|c|}{ Number of subjects } & 14 & 29 & 25 & 56 & 30 & 129 & 21 & 110 & 15 \\
\hline \multicolumn{2}{|c|}{ Aggregate loss (cm) } & 2.31 & 1.36 & 2.07 & 1.3 & 1.7 & 1.09 & 2.12 & 1.29 & 3.07 \\
\hline
\end{tabular}

For cluster analysis based size charts, the value of one control dimension mentioned in the size chart indicates the central value of that interval. An example of a size chart for class 1 (waist girth-waist height) is shown in Table 8. An interval of 5 centimetres has been kept for the control dimensions. For example, waist girth 57 centimetres as mentioned in the size charts covers waist girth more than or equal to 55 centimetres and less than 60 centimetres $(55 \mathrm{~cm} \leq$ waist girth $<60 \mathrm{~cm})$. The same method is followed for the other control dimensions also.

For standard deviation based size charts, the value of one control dimension mentioned in the size chart indicates the central value of the standard deviation range. For example, height, 156 centimetres as mentioned in the size chart covers height more than or equal to 153 centimetres and less than 159 centimetres $(153 \mathrm{~cm} \leq$ height $<159 \mathrm{~cm})$, since the standard deviation of that control dimension is 6 centimetres. The value mentioned for the secondary dimension against each size category is the average value of the body dimensions of the subjects falling in the respective size category. 
It was observed from the size chart (refer Table 8), that there are five waist girth categories and for each such category there are waist height sub-categories. As indicated for the waist girth category of $62 \mathrm{~cm}$, there are 3 waist height subcategories $92 \mathrm{~cm}$, $97 \mathrm{~cm}$, and $102 \mathrm{~cm}$. As a result, in this size chart for class 1, there are total of 9 size categories or size rolls. The number of subjects and aggregate loss value of each category is indicated (refer to Table 9). It was observed that this percentage coverage of this size chart was $78.55 \%$ spanning 32 size categories with average aggregate loss of $1.81 \mathrm{~cm}$.

\section{Validation of size charts}

McCulloch et al. (1998) proposed the method for quantification of fit in a size chart. The level of fit is said to be poor with an increase in the deviation of individual's measurements from the prototype. Ashdown (1998) stated that aggregate loss represents the level of fit in the sizing system and is calculated by averaging out all the individuals' distances from respectively assigned size. Aggregate loss based on Euclidean distance between two points $\mathrm{X}\left(\mathrm{X}_{1}, \mathrm{X}_{2}\right.$, etc. $)$ and $\mathrm{Y}\left(\mathrm{Y}_{1}, \mathrm{Y}_{2}\right.$, etc. $)$ is calculated as:

$$
\text { Euclidean distance }(d)=\sqrt{\sum_{i=1}^{n}\left(x_{i}-y_{i}\right)^{2}}
$$

where $x_{i}$ and $y_{i}$ are the coordinates of points where $x$ is the actual size and $y$ is the assigned size for the $j^{\text {th }}$ axis to represent the $j^{\text {th }}$ dimension.

The system with an ability to provide the best fit should confirm the aggregate loss as low as possible (Ashdown, 1998). The validation of size chart developed was done by determining the degree of fit following Euclidian distance as a measure of aggregate loss. In recent times, the aggregate loss is widely used by researchers worldwide for size chart validation and treated as a reliable tool for measuring the goodness of fit. Ideal aggregate loss value of fit may be a number given by the square root of the number of control dimensions or primary dimensions considered, allowing for $+/-1$-inch deviation of the body dimension from the assigned value. Hence aggregate loss value (goodness of fit value) when considering two control body dimensions may be $\sqrt{2}$ or 1.414 inches. The same value in the metric system will be $3.59 \sim 3.6 \mathrm{~cm}$. For fit validation of body size chart with two control dimensions, the aggregate loss value should be equal or lesser than $3.6 \mathrm{~cm}$.

In this research, each size category of every size chart was validated using aggregate loss based on Euclidean distance. All the six size charts developed were validated by calculating on an average aggregate loss. As mentioned in Table 10 the aggregate loss values observed from $1.81 \mathrm{~cm}$ to $2.42 \mathrm{~cm}$ in the size charts developed in this research. These values fall well within the standard limit value of $\leq 3.60 \mathrm{~cm}$. The aggregate loss values observed in this research were found at par with the findings of other research works carried out in this field worldwide. Hsu (2009b) developed a data mining framework for industrial standards and observed aggregate loss values ranged between $2.5 \mathrm{~cm}$ and $3.3 \mathrm{~cm}$. Zakaria (2011) validated the body size charts of the Malaysian school children using aggregate loss based on the Euclidean distance. The aggregate loss values observed were between $2.5 \mathrm{~cm}$ and $2.6 \mathrm{~cm}$ while using two control dimensions (Zakaria, 2011). Doustaneh et al. (2010) validated the size charts using aggregate loss and observed 
aggregate loss values between $2.27 \mathrm{~cm}$ and $5.18 \mathrm{~cm}$. It was noted that the aggregate loss observed in this research was, in fact, lesser than the aggregate loss observed by other researchers in recent times. It confirms the good level of fit and accuracy offered by the size charts developed in this research.

Table 9 Size distribution for waist girth-waist height combination

\begin{tabular}{|c|c|c|c|c|c|c|c|}
\hline \multirow{2}{*}{$\begin{array}{l}\text { Size } \\
\text { roll }\end{array}$} & \multirow{2}{*}{ Class } & \multicolumn{2}{|c|}{$\begin{array}{c}\text { Control dimensions } \\
(\mathrm{cm})\end{array}$} & \multirow{2}{*}{$\begin{array}{l}\text { Number of } \\
\text { subjects }\end{array}$} & \multirow{2}{*}{$\begin{array}{c}\% \\
\text { accommodation }\end{array}$} & \multirow{2}{*}{$\begin{array}{l}\text { Aggregate } \\
\text { loss value } \\
\quad(\mathrm{cm})\end{array}$} & \multirow{2}{*}{$\begin{array}{c}\text { Average } \\
\text { aggregate } \\
\text { loss value } \\
\quad(\mathrm{cm})\end{array}$} \\
\hline & & $\begin{array}{l}\text { Waist } \\
\text { girth }\end{array}$ & $\begin{array}{l}\text { Waist } \\
\text { height }\end{array}$ & & & & \\
\hline 1 & \multirow[t]{9}{*}{1} & 57 & 102 & 14 & $0.58 \%$ & 2.31 & \multirow[t]{33}{*}{1.81} \\
\hline 2 & & 62 & 92 & 29 & $1.21 \%$ & 1.36 & \\
\hline 3 & & & 97 & 25 & $1.04 \%$ & 2.07 & \\
\hline 4 & & & 102 & 56 & $2.33 \%$ & 1.30 & \\
\hline 5 & & 67 & 97 & 30 & $1.25 \%$ & 1.70 & \\
\hline 6 & & & 102 & 129 & $5.37 \%$ & 1.10 & \\
\hline 7 & & 72 & 97 & 21 & $0.87 \%$ & 2.12 & \\
\hline 8 & & & 102 & 110 & $4.58 \%$ & 1.30 & \\
\hline 9 & & 77 & 97 & 15 & $0.62 \%$ & 3.07 & \\
\hline 10 & \multirow[t]{10}{*}{2} & \multirow[t]{2}{*}{62} & 107 & 43 & $1.79 \%$ & 1.46 & \\
\hline 11 & & & 112 & 58 & $2.42 \%$ & 1.20 & \\
\hline 12 & & \multirow[t]{3}{*}{67} & 107 & 104 & $4.33 \%$ & 1.21 & \\
\hline 13 & & & 112 & 110 & $4.58 \%$ & 1.21 & \\
\hline 14 & & & 117 & 26 & $1.08 \%$ & 1.90 & \\
\hline 15 & & \multirow[t]{3}{*}{72} & 107 & 159 & $6.62 \%$ & 1.26 & \\
\hline 16 & & & 112 & 187 & $7.79 \%$ & 1.18 & \\
\hline 17 & & & 117 & 54 & $2.25 \%$ & 1.31 & \\
\hline 18 & & \multirow[t]{2}{*}{77} & 112 & 101 & $4.21 \%$ & 1.12 & \\
\hline 19 & & & 117 & 71 & $2.96 \%$ & 2.33 & \\
\hline 20 & \multirow[t]{13}{*}{3} & \multirow[t]{2}{*}{77} & 102 & 42 & $1.75 \%$ & 1.61 & \\
\hline 21 & & & 107 & 110 & $4.58 \%$ & 1.45 & \\
\hline 22 & & \multirow[t]{5}{*}{82} & 97 & 14 & $0.58 \%$ & 3.56 & \\
\hline 23 & & & 102 & 46 & $1.92 \%$ & 1.48 & \\
\hline 24 & & & 107 & 91 & $3.79 \%$ & 1.57 & \\
\hline 25 & & & 112 & 79 & $3.29 \%$ & 2.01 & \\
\hline 26 & & & 117 & 16 & $0.67 \%$ & 2.54 & \\
\hline 27 & & \multirow[t]{4}{*}{87} & 102 & 25 & $1.04 \%$ & 2.36 & \\
\hline 28 & & & 107 & 37 & $1.54 \%$ & 1.87 & \\
\hline 29 & & & 112 & 29 & $1.21 \%$ & 1.72 & \\
\hline 30 & & & 117 & 18 & $0.75 \%$ & 2.17 & \\
\hline 31 & & \multirow[t]{2}{*}{92} & 107 & 18 & $0.75 \%$ & 2.69 & \\
\hline 32 & & & 112 & 19 & $0.79 \%$ & 2.53 & \\
\hline \multicolumn{4}{|c|}{ Total subjects covered } & 1,886 & $78.55 \%$ & & \\
\hline
\end{tabular}




\section{Comparative analysis of the size charts developed}

According to McCulloch et al. (1998), an effective and economical sizing system must meet objectives of minimum aggregate loss, minimum number of size categories and maximized percentage coverage of the population. A comparative analysis was done for all the six size charts developed following the evaluation criteria suggested by McCulloch et al. (1998). The percentage coverage of population values was observed from $76.22 \%$ to $97.21 \%$ and considered as good accommodation in comparison to the international standards. A size chart with coverage of population ranging between $65 \%$ and $80 \%$ is treated as satisfactory (Petrova, 2007; Gupta and Zakaria, 2014a).

Table 10 Size charts comparison

\begin{tabular}{cccccc}
\hline $\begin{array}{l}\text { Sr. } \\
\text { no. }\end{array}$ & $\begin{array}{c}\text { Size chart control } \\
\text { dimensions }\end{array}$ & $\begin{array}{c}\text { Method } \\
\text { used }\end{array}$ & $\begin{array}{c}\text { Total size } \\
\text { categories }\end{array}$ & $\begin{array}{c}\text { Aggregate loss } \\
\text { value achieved }\end{array}$ & $\begin{array}{c}\text { \% coverage of } \\
\text { population }\end{array}$ \\
\hline 1 & WG-H & Cluster & 40 & 2.21 & $83.38 \%$ \\
2 & WG-WH & analysis & 32 & 1.81 & $78.55 \%$ \\
3 & WG-CH & & 35 & 2.34 & $76.22 \%$ \\
4 & WG-H & Standard & 40 & 2.41 & $92.13 \%$ \\
5 & WG-WH & deviation & 40 & 2.42 & $95.50 \%$ \\
6 & WG-CH & & 39 & 2.29 & $97.21 \%$ \\
\hline
\end{tabular}

As shown in Table 10, it was noted that the size charts developed based on cluster analysis classification witnessed lesser aggregate loss values (confirmed better fit). While two of the size charts from this category had a lesser number of size categories as 32 and 35. However, these two size charts witnessed a comparatively lesser accommodation percentage (76-79\%) though it was well within the acceptable limits. Standard deviation based size charts showed an aggregate loss, number of size categories comparatively higher than cluster analysis, though it too was well within the acceptable limits. These size charts (standard deviation based) showed excellent accommodation percentage (92-97\%). The reason for this result may be the range considered for key dimensions that were mean $+/-3 \mathrm{SD}$. As the anthropometric data of subjects was near normally distributed, and in a normal distribution, mean $+/-3$ SD limits cover approximately $99 \%$ of the population.

\section{Conclusions}

All the six size charts developed were validated by measuring aggregate loss based on Euclidean distance. The aggregate loss values observed from $1.81 \mathrm{~cm}$ to $2.42 \mathrm{~cm}$. These values fall well within the standard limit value of $\leq 3.60 \mathrm{~cm}$ The percentage coverage of population values was observed from $76.22 \%$ to $97.21 \%$ with 32 to 40 size categories. It is considered as a good accommodation to the international standards. Size chart number 2 (WG-WH - cluster analysis) was observed best with minimum aggregate loss value and the number of size categories, while size chart number 6 (WG-CH - standard deviation) was observed best on the grounds of maximum percentage coverage of the population. 
This study applied data mining on the anthropometric data to develop the body size charts for bottom-wear. Proposed method ensured higher accommodation rate and lesser aggregate loss with lesser number of size categories in comparison to the standard values. The results of the study may help the mass manufacturers in predicting the proportional quantities in the respective sizes. It may also help the manufacturers and distributors in an effective process planning and control at different levels of the apparel supply chain. The garments developed using the proposed size charts may result in increased consumer satisfaction and reduction in loss of sales because of fit issues of bottom-wear.

The research addresses one of the immediate needs of the Indian apparel sector by creating the first ever comprehensive body size charts of bottom-wear for young Indian male (18-29 years) achieved through nationwide anthropometric survey.

\subsection{Research limitations}

As some of the limitations, it may be noted that though statistically justified sample size has been followed from each geographical region covering all the states of India, the representation of people from individual state may vary. Also, the native place of the subjects has been recorded while undertaking body size survey, yet there is a possibility that it might not reflect the actual native place due to migration of the participants and /or their family in past.

\subsection{Research scope}

1 The garment size charts should be developed from the body size charts proposed in this research, and fit of garments is recommended to be tested by the mass manufacturers of bottom-wear. This may enhance the usefulness and practical applications of this research.

2 Different advanced tools and techniques are recommended to be applied for data classification and development of size systems. Advanced machine learning methods based on neural networks, artificial intelligence and genetic algorithms should be explored on the anthropometric data of this research. Application of such advanced techniques may result in more promising and efficient size systems. The anthropometric data of this research may be utilised in developing predictive models for getting better fit solutions.

3 Regression analysis should be explored in a detailed manner and some regression equations may be developed which can accurately estimate the body dimensions (which are tricky to measure) using some key dimensions which are easy to measure and familiar to all stakeholders.

4 People of other age groups, gender and product categories may be covered as an extension of this research. 


\section{References}

Aldrich, W. (2006) Metric Pattern Cutting for Menswear, 4th ed., Blackwell Publishing, Oxford, UK.

Anand, N. (2011) Size Does Matter - Need for 'SizeIndia' - National Body Sizing Survey of India, [TC] 2 [online] http://www.techexchange.com/library/Size\%20does\%20matter\%20-\%20Need \%20for\%20Size\%20India\%20-\%20National\%20Body\%20Sizing\%20Survey\%20of

\%20Indian.pdf (accessed 18 July 2012).

Armstrong, H. (2006) Patternmaking for Fashion Design, 4th ed., Pearson Eduction, Inc., New Jersey, USA.

Ashdown, S.P. (1998) 'An investigation of the structure of sizing systems - a comparison of three multidimensional optimized sizing systems generated from anthropometric data with the ASTM Standard D5585-94', International Journal of Clothing Science and Technology, Vol. 10, No. 5, pp.324-341.

Bartlett, J.E., Kotrlik, J.W. and Higgins, C. (2001) 'Organizational research: determining appropriate sample size in survey research', Information Technology, Learning and Performance Journal, Vol. 19, No. 1, pp.43-50.

Beazley, A. (1997) 'Size and fit: procedures in undertaking a survey of body measurements', Journal of Fashion Marketing and Management: An International Journal, Vol. 2, No. 1, pp.55-85.

Bridger, R.S. (2003) Introduction to Ergonomics, Taylor \& Francis, UK.

Chakrabarty, D. (1997) Indian Anthropometric Dimensions: For Ergonomic Design Practice, National Institute of Design, Ahmedabad.

Chun, J. (2014) 'International apparel sizing systems and standardization of apparel sizes', in Gupta, D. and Zakaria, N. (Eds.): Anthropometry, Apparel Sizing and Design, pp.289-291, Woodhead Publishing Ltd. in Association with The Textile Institute, Cambridge, UK.

Chung, M-J., Lin, H-F. and Wang, M-J.J. (2007) 'The development of sizing systems for Taiwanese elementary and high-school students', International Journal of Industrial Ergonomics, Vol. 37, No. 8, pp.707-716.

Chun-Yoon, J. and Jasper, C.R. (1993) 'Garment-sizing systems: an international comparison', International Journal of Clothing Science and Technology, Vol. 5, No. 5, pp.28-37.

Cooklin, G. (1992) Pattern Grading for Men's Clothes, Blackwell Scientific, London, UK.

Doustaneh, A., Gorji, M. and Varsei, M. (2010) 'Using Self-organizing method (SOM) to establish a non-linear sizing system', World Applied Sciences Journal, Vol. 9, No. 12, pp.1359-1364.

Government of India - Ministry of Youth and Sports (2014) National Youth Policy, Government of India, New Delhi, India.

Gupta, D. (2008) Indian Body Dimensions [online] http://www.techexchange.com/library/ Indian\%20Body\%20Dimensions.pdf (accessed 25 June 2010).

Gupta, D. (2010) 'Anthropometric study of young Indian men for garment sizing', Research Journal of Textile and Apparel, Vol. 14, No. 1, pp.82-89.

Gupta, D. and Zakaria, N. (2014a) 'Apparel sizing: existing sizing systems and the development of new sizing systems', in Gupta, D. and Zakaria, N. (Eds.): Anthropometry, Apparel Sizing and Design, pp.3-33, Woodhead Publishing Limited in Association with the Textile Institute, Cambridge.

Gupta, D. and Zakaria, N. (Eds.) (2014b) Anthropometry, Apparel Sizing and Design, Woodhead Publishing Limited in Association with the Textile Institute, Cambridge.

Hrženjak, D.K.R. and Ujevic, D. (2015) 'Sizing system for girls aged 13-20 years based on body types', Textile Research Journal, Vol. 85, No. 12, pp.1293-1304.

Hsu, C-H. (2009a) 'Data mining to improve industrial standards and enhance production and marketing: an empirical study in apparel industry', Expert Systems with Applications, Vol. 36, pp.4185-4191. 
Hsu, C-H. (2009b) 'Developing accurate industrial standards to facilitate production in apparel manufacturing based on anthropometric data', Human Factors and Ergonomics in Manufacturing, Vol. 19, No. 3, pp.199-211.

ISO 3636 (1997) ISO 3636:1977/Cor.1: 1990 Size designation of clothes - Men's and boys' outerwear garments, ISO, Geneva, 1977.

ISO 7250(I) (2008) Basic Human Body Measurements for Technological Design - Body Measurement Definitions and Landmarks (Part-1), ISO, Geneva, 2008.

ISO 8559 (1989) Garment Construction and Anthropometric Surveys - Body Dimensions, International Organization for Standardization, Geneva.

Kunick, P. (1984) Modern Sizing and Pattern Making for Women's and Children Garments, Kunick Publications, London.

Levin, L.R. and Rubin, S.D. (2004) Statistics for Management, 7th ed., Pearson Education, Pte. Limited, Singapore.

McCulloch, C.E., Paal, B. and Ashdown, S.P. (1998) 'An optimization approach to apparel sizing', Journal of the Operational Research Society, Vol. 49, pp.492-499.

Moon, J.Y. and Nam, Y.J. (2003) 'A study the elderly women's lower figure type classification and lower garment sizing systems', Proceedings of International Ergonomics Association, Korea.

NTC (2003) NTC Project: S01-CR01 (Formerly S01-B01), 2003: Use of Body Scan Data to Design Sizing Systems Based on Target Markets, National Textile Center.

Petrova, A. (2007) 'Creating sizing systems', in Ashdown, S.P. (Ed.): Sizing in Clothing, pp.57-87, Woodhead Publishing Limited, Cambridge, UK.

Pheasant, S. and Haslegrave, C.M. (2006) BODY SPACE - Anthropometry, Ergonomics and the Design of Work, 3rd ed., CRC Press-Taylor \& Francis Group, New York.

Shodhganga-Inflibnet (2013) Determination of appropriate Sample Size [online] http://shodhganga.inflibnet.ac.in. (accessed 20 January 2016).

Zakaria, N. (2011) 'Sizing system for functional clothing - uniforms for school children', Indian Journal of Fibre \& Textile Research, Vol. 36, No. 4, pp.348-357.

Zakaria, N. (2014) 'Body shape analysis and identification of key dimensions for apparel sizing systems', in Gupta, D. and Zakaria, N. (Eds.): Anthropometry, Apparel Sizing and Design, p.98, Woodhead Publishing Limited, Cambridge, UK. 